Vol. 11 (3): 449-452 (2021)

\title{
UNUSUAL DURATION OF HASHITOXICOSIS IN A PATIENT WITH HASHIMOTO'S THYROIDITIS: CASE STUDY
}

\author{
Yllka Themeli ${ }^{1,2^{*}}$, Vjollca Ndreu $^{1}$ \\ ${ }^{1 *}$ University of Medicine, Faculty of Technical Medical Sciences, Tirana, Albania; \\ ${ }^{2}$ Diagnostic Center "DIAMED", Tirana, Albania; \\ *Corresponding Author Yllka Themeli, e-mail: yllkathemeli@gmail.com;
}

Received March 2021; Accepted April 2021; Published May 2021;

DOI: https://doi.org/10.31407/ijees11.312

\begin{abstract}
Hashimoto's thyroiditis is a chronic autoimmune disease, which causes a gradual decrease in the production of thyroid hormones. This case study shows a woman aged 32 presented with typical hashitoxicosis symptoms. All three thyroid antibodies were elevated. Based on the clinical manifestations, physical examination and biochemical tests, an initial diagnosis of Grave's disease was made. Only after 14 months after starting the treatment the level of Thyroid Stimulating Hormone (TSH) began to increase gradually and the definitive diagnosis was Hashimoto's thyroiditis with Hypothyroidism. After that, the patient started the permanent replacement therapy with levothyroxine and remained euthyroid on levothyroxine. The case highlights the importance of thyroid ultrasound and scintigraphy at the moment of diagnosis, followed by regular biochemical tests and endocrinological consultations as the only way to avoid unnecessary radioactive iodine therapy for the patient.
\end{abstract}

Key words: Hashimoto's thyroiditis, Hashitoxicosis, Case report,Thyroid ultrasound, Thyroid,Scintigraphy. 